Article

\title{
Supramolecular Strategy Effects on Chitosan Bead Stability in Acidic Media: A Comparative Study
}

\author{
Andrew J. Worthen, Kelly S. Irving and Yakov Lapitsky *(i) \\ Department of Chemical Engineering, University of Toledo, Toledo, OH 43606, USA; \\ andrew.worthen@utoledo.edu (A.J.W.); kelly.irving@utoledo.edu (K.S.I.) \\ * Correspondence: yakov.lapitsky@utoledo.edu; Tel.: +1-419-530-8254
}

Received: 31 December 2018; Accepted: 16 February 2019; Published: 25 February 2019

check for updates

\begin{abstract}
Chitosan beads attract interest in diverse applications, including drug delivery, biocatalysis and water treatment. They can be formed through several supramolecular pathways, ranging from phase inversion in alkaline solutions, to the ionic crosslinking of chitosan with multivalent anions, to polyelectrolyte or surfactant/polyelectrolyte complexation. Many chitosan bead uses require control over their stability to dissolution. To help elucidate how this stability depends on the choice of supramolecular gelation chemistry, we present a comparative study of chitosan bead stability in acidic aqueous media using three common classes of supramolecular chitosan beads: (1) alkaline solution-derived beads, prepared through simple precipitation in $\mathrm{NaOH}$ solution;

(2) ionically-crosslinked beads, prepared using tripolyphosphate (TPP); and (3) surfactant-crosslinked beads prepared via surfactant/polyelectrolyte complexation using sodium salts of dodecyl sulfate (SDS), caprate $\left(\mathrm{NaC}_{10}\right)$ and laurate $\left(\mathrm{NaC}_{12}\right)$. Highly variable bead stabilities with dissimilar sensitivities to $\mathrm{pH}$ were achieved using these methods. At low $\mathrm{pH}$ levels (e.g., $\mathrm{pH}$ 1.2), chitosan/SDS beads were the most stable, requiring roughly 2 days to dissolve. In weakly acidic media (at $\mathrm{pH}$ 3.0-5.0), however, chitosan/TPP beads exhibited the highest stability, remaining intact throughout the entire experiment. Beads prepared using only $\mathrm{NaOH}$ solution (i.e., without ionic crosslinking or surfactant complexation) were the least stable, except at $\mathrm{pH}$ 5.0, where the $\mathrm{NaC}_{10}$ and $\mathrm{NaC}_{12}$-derived beads dissolved slightly faster. Collectively, these findings provide further guidelines for tailoring supramolecular chitosan bead stability in acidic media.
\end{abstract}

Keywords: chitosan; gel beads; stability; dissolution

\section{Introduction}

Chitosan is a bioderived polysaccharide that is produced through the deacetylation of chitin [1,2]. Due to its low toxicity [3,4] and ability to form an assortment of useful intermolecular complexes [5-7], chitosan attracts widespread interest in biomedical [8,9], biotechnological [10,11], environmental [12,13], food [14,15], and home and personal care [2] technologies. Chemically, chitosan is a random copolymer of $\beta$-(1-4)-linked D-glucosamine and $N$-acetyl-D-glucosamine monomer units, whose fraction of D-glucosamine units is known as its degree of deacetylation (DD) [1,2]. The ionizable D-glucosamine amine groups have an effective $\mathrm{p} K_{a}$ of $c a$. 6.0-6.5, above which chitosan is typically insoluble, and below which chitosan is soluble $[1,16]$.

When its amine groups are protonated, chitosan becomes a polyelectrolyte that can be assembled into diverse, gel-like soft materials $[5,6,8,9]$. These range from films and coatings $[17,18]$, to fibers $[19,20]$, colloidal particles $[8,21,22]$, and macroscopic gels $[9,23]$ and beads $[13,24-26]$. These materials can be prepared using diverse supramolecular strategies, which include ionic crosslinking of chitosan with multivalent ions [18,21,26], complexation of chitosan with anionic surfactants $[13,19,24]$ or polymers [9,20,22,23], and precipitation of chitosan in alkaline solutions [11,13]. 
A key property that determines the performance of these chitosan-based materials is their degradation stability, which can be limited by either hydrolytic degradation of the chitosan chains [27-29] or simple dissolution [18,30-33]. Under dissolution-free conditions, which typically arise at neutral or alkaline $\mathrm{pH}$ (where chitosan is insoluble), or situations where the chitosan is essentially irreversibly crosslinked, the degradation of chitosan-based materials is controlled by hydrolytic chain scission $[27,34]$. The rate of this scission varies with the chitosan DD and, because it is slow for highly deacetylated chitosan, chitosan-based materials can (at least at near-neutral $\mathrm{pH}$ ) remain intact over many weeks or months [27-29,35]. Conversely, when chitosan-based materials are prepared through reversible supramolecular crosslinking/association (using some of the strategies described above) and stored under acidic conditions (under which chitosan is soluble), chitosan chain scission tends not to be the stability-limiting factor. Instead, the dissolution stability in these cases depends on the supramolecular association strength (either between the chitosan chains or the chitosan and crosslinker $[7,18,30,36])$ and, in cases where a physical crosslinker is used, the crosslinker content within the chitosan network [26,32]. Previous stability studies revealed the association strength and, consequently, the stability of supramolecular chitosan-based materials to depend on the chitosan $\mathrm{DD}[30,37], \mathrm{pH}[18,26,32]$ and ionic strength $[18,30]$ of the dissolution media, and the molecular structure of the crosslinking/gelling agent $[7,18,38]$.

To date, there have been many studies examining the stability of ionically crosslinked nanoparticles [30,39], films [7,32], and beads [26,38], as well as some investigating gels formed through complexation of chitosan and its derivatives with oppositely charged polyelectrolytes [31,40] and surfactants $[33,36]$. Yet, aside from some reports comparing chitosan complexation with small multivalent ions with chitosan-based polyelectrolyte complex formation [31,40], and studying the effects of various covalent and ionic crosslink types [7,38], there is a dearth of studies that directly compare the stability of self-assembled chitosan gels prepared through disparate mechanisms (e.g., alkaline precipitation versus ionic crosslinking, and polyelectrolyte and surfactant/polyelectrolyte complexation). To partially address this and provide further guidelines for designing supramolecular chitosan complexes, here we investigate the stability of chitosan-based beads in acidic aqueous solutions using beads prepared by three different supramolecular mechanisms: (1) precipitation in alkaline solution, (2) complexation with anionic surfactant, and (3) ionic crosslinking with tripolyphosphate (TPP), which is a common (and highly potent) ionic chitosan crosslinker [7,8,26,38]. Specifically, we focus on acidic conditions $(\mathrm{pH}=1.2-5.0)$, which exist in many common chitosan applications (e.g., pharmaceutics, food and water treatment $[7,12,15])$ and at which chitosan is water-soluble. Using visual observations and stereomicroscopy to monitor bead dissolution, dissolution stabilities of the above bead types (i.e., their dissolution times and changes in external appearance) are systematically analyzed and compared.

\section{Results and Discussion}

\subsection{Alkaline Solution-Derived Beads}

Supramolecular chitosan beads were generated via dropwise addition of a $3 \mathrm{wt} \%$ aqueous chitosan solution ( $\mathrm{pH} .5 .0$ ) into either $0.1 \mathrm{M} \mathrm{NaOH}$ or $1 \mathrm{wt} \% \mathrm{TPP}$, sodium caprate $\left(\mathrm{NaC}_{10}\right)$, sodium laurate $\left(\mathrm{NaC}_{12}\right)$ or sodium dodecyl sulfate (SDS) solutions through a 20-gauge syringe needle and equilibrating the resulting mixtures (which successfully formed millimeter-scale spherical beads) at $30{ }^{\circ} \mathrm{C}$ for at least $24 \mathrm{~h}$. Here, the $1 \mathrm{wt} \%$ ionic crosslinker/surfactant concentrations were selected to remain fixed (so that their molecular structure alone was varied) and to safely not exceed the solubility limit of the least soluble surfactant, $\mathrm{NaC}_{12}$ [41]. Upon equilibration, single beads were placed into the dissolution media (10 mM of aqueous $\mathrm{NaCl}$ solutions at varying, 1.2-5.0 $\mathrm{pH}$ levels) and monitored for dissolution by: (1) imaging the beads via stereomicroscopy; and (2) visually determining the times at which their full dissolution occurred. 
Since chitosan is soluble at acidic $\mathrm{pH}$ levels $[1,16]$, beads formed through precipitation in $\mathrm{NaOH}$ solutions all eventually dissolved in the acidic dissolution media. The timescales of this dissolution, however, were highly $\mathrm{pH}$-dependent. At $\mathrm{pH} 5.0$ (the highest examined dissolution $\mathrm{pH}$ ), the beads remained outwardly unchanged over the first several hours. After $8 \mathrm{~h}$, however, the beads began to slowly shrink, and after $16 \mathrm{~h}$, they began to deform (Figure 1 ). This deformation increased substantially after $24 \mathrm{~h}$, whereupon the initially rigid (and highly opaque) beads became both soft and more translucent (Figure 1). Within a few hours of losing their rigidity, the beads started to rapidly shrink (due to their accelerated dissolution), until completely dissolving after roughly $30 \mathrm{~h}$ (Figure 2).

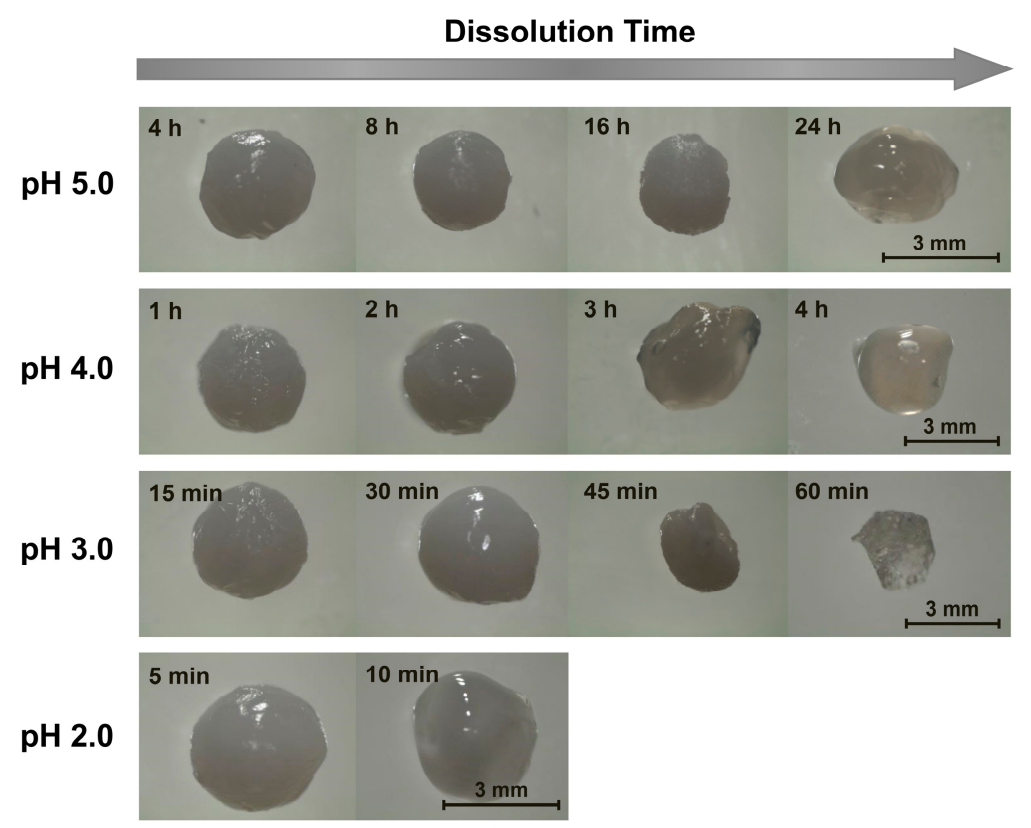

Figure 1. Representative images of alkaline solution-derived chitosan beads dissolving in $\mathrm{pH} 1.2-5.0$ aqueous solutions $([\mathrm{NaCl}]=10 \mathrm{mM})$.

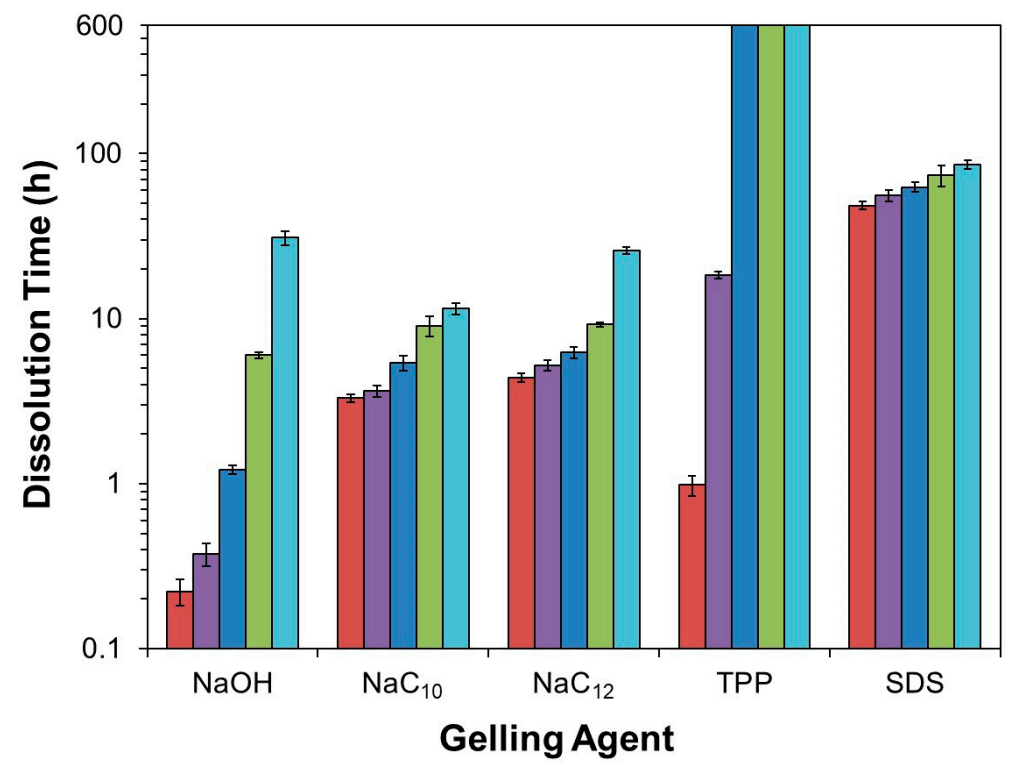

Figure 2. Summary of bead dissolution times in $10 \mathrm{mM}$ aqueous $\mathrm{NaCl}$ solutions at $\mathrm{pH}(\square) 1.2$, (口) 2.0,

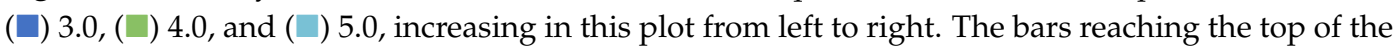
plot for the chitosan/TPP beads at $\mathrm{pH}$ 3.0-5.0 indicate that these beads remained intact throughout the entire experiment. For all other conditions, error bars representing one standard deviation in bead dissolution time are given $(n=6)$. 
When the experiments were repeated in more acidic, $\mathrm{pH} 4.0$ dissolution media, the dissolution time diminished sharply to approximately $6 \mathrm{~h}$ (Figure 2). Here, the beads began to deform and swell after just $3 \mathrm{~h}$ of dissolution, and started to become transparent and shrink after $4 \mathrm{~h}$ (Figure 1). When the dissolution media $\mathrm{pH}$ was decreased to $\mathrm{pH}$ 3.0, bead dissolution became even faster (occurring in just slightly over $1 \mathrm{~h}$; Figure 2). The evolution in the bead morphology, however, was different than that in less acidic media. After appearing to remain unchanged over the first $15 \mathrm{~min}$, the beads swelled slightly after $30 \mathrm{~min}$, shrank and became less spherical after $45 \mathrm{~min}$, and became almost flat and flake-like after $60 \mathrm{~min}$ (Figure 1).

In the limit of very low $\mathrm{pH}$ values of 2.0 and 1.2, the dissolution was accelerated to the point where it became difficult to image the dissolving beads. At $\mathrm{pH} 2.0$, the beads began shrinking after $5 \mathrm{~min}$ and started to become more transparent after $10 \mathrm{~min}$ (Figure 1). After $15 \mathrm{~min}$ the beads became completely transparent, whereupon they were fully dissolved in slightly over 20 min (Figure 2). This rapid dissolution became even faster at $\mathrm{pH} 1.2$, which was similar to the gastric environment encountered by orally administered capsules. The beads shrank substantially after only 1 min of dissolution, were almost completed dissolved after a few $\mathrm{min}$, and were fully dissolved after about $10 \mathrm{~min}$ in the dissolution media (Figure 2). This ready dissolution of uncrosslinked chitosan beads was consistent with reports by Lipatova and Makharova, who showed chitosan flakes to dissolve in acetic acid solution over the timescale of hours [42], and by Wan Ngah et al., who reported uncrosslinked chitosan beads to dissolve in $5 \mathrm{vol} \%$ acetic acid solutions [43]. These rapid dissolution times show that alkaline solution-derived chitosan beads are highly unstable in the limit of low $\mathrm{pH}$ levels, such as those encountered by orally administered drug formulations in the gastric fluid, but can withstand mildly acidic media (such as may exist in food formulations or during bioprocessing) on the timescale of hours.

\subsection{Tripolyphosphate-Crosslinked Beads}

Unsurprisingly, when the beads were ionically crosslinked with TPP, their stability to dissolution in acidic environments increased. In milder acidic media $(3.0 \leq \mathrm{pH} \leq 5.0)$, the beads persisted throughout the entire 7-day quantitative dissolution experiment (Figure 2) and exhibited almost no change in appearance (Figure 3). Yet, though this lack of change over 7 days indicates the beads to be much more stable in mildly acidic media than their alkaline solution-derived counterparts, it does not mean that the beads remain stable indefinitely. Indeed, imaging the beads placed in $\mathrm{pH} 5.0$ solution over longer (28-day) timescales revealed that the beads began to swell (see Figure 3), which hinted at their slow dissociation and dissolution [31]. This progression likely reflects the slow leaching of crosslinking TPP ions [26,30] and indicates limits to the stability of these chitosan/TPP networks.

The bead stability was even more limited when the beads were placed in highly acidic pH 1.2-2.0 media. At pH 2.0, for instance, the opaque beads became both swollen and translucent after $12 \mathrm{~h}$, and fully dissolved after roughly $18 \mathrm{~h}$ (Figures 2 and 3). Similarly, at $\mathrm{pH} 1.2$, the beads became transparent after just $45 \mathrm{~min}$ and completely dissolved in roughly $1 \mathrm{~h}$. This sharp $\mathrm{pH}$ effect on the bead stability reflects the impact of $\mathrm{pH}$ on chitosan/TPP binding strength. TPP is a polyprotic acid $\left(\mathrm{p} K_{a, 3}=2.8\right.$, $\mathrm{p} K_{a, 4}=6.5$, and $\mathrm{p} K_{a, 5}=9.2$ [44]) and, at low $\mathrm{pH}$ levels, becomes partially protonated. This protonation reduces TPP ionization and, accordingly, weakens its binding to cationic chitosan and causes the beads to dissolve in highly acidic media. This observation is qualitatively consistent with those reported by Jóźwiak et al., who reported chitosan/TPP beads to rapidly dissolve at $\mathrm{pH} 2.0$ and (when the beads had a low TPP content) 3.0 [38], and by Mi et al., who reported the phosphorus elution to increase sharply at low (1.2-3.0) pH levels [26]. Yet, Mi et al. indicated chitosan/TPP beads formed at very high TPP contents (achieved using much more concentrated, $10 \mathrm{wt} \%$ TPP solutions at low $\mathrm{pH}$ levels) could be maintained intact for up to $1-2$ days, even at $\mathrm{pH} 1.0[26,40]$. This was evidently because the initial TPP content within these beads was high enough (at least in a batch experiment without solvent replacement) to prevent bead swelling and dissolution, even when $>30 \%$ of the TPP leached from the beads [26]. Thus, it may be possible to increase the bead dissolution times in Figure 2 by 
increasing their TPP content $[26,32,40]$ or (since chitosan/TPP binding strength increases with the chitosan DD [30]) using chitosan with even higher DD values. Despite these possibilities, at the $1 \mathrm{wt} \%$ TPP concentrations (with no $\mathrm{pH}$ adjustments) used in the present work, ionic crosslinking with TPP stabilizes chitosan beads in moderately acidic media (e.g., at $3.0 \leq \mathrm{pH} \leq 5.0$ ), but provides only modest improvements in bead stability at the highly acidic $\mathrm{pH}$ of gastric fluid.

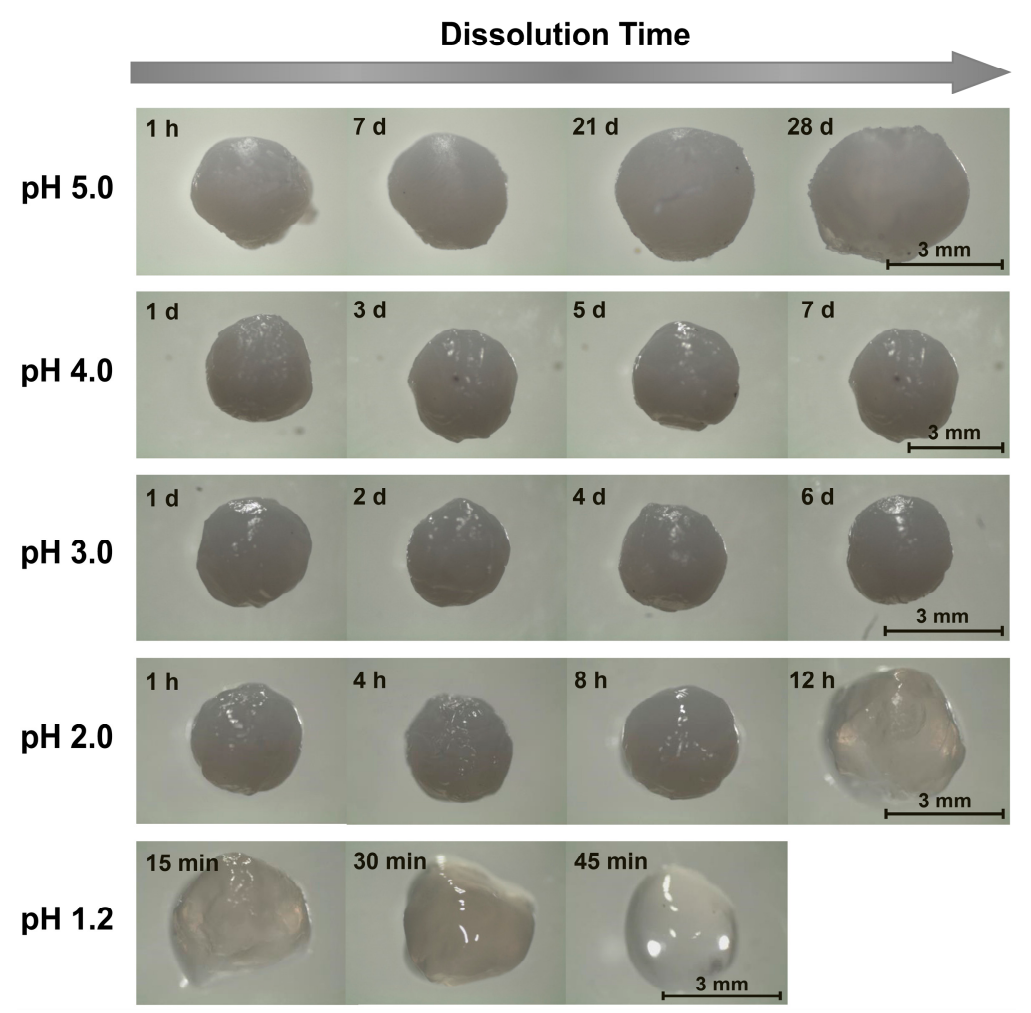

Figure 3. Representative images of chitosan/TPP beads dissolving in $\mathrm{pH} 1.2-5.0$ aqueous solutions $([\mathrm{NaCl}]=10 \mathrm{mM})$.

\subsection{Surfactant-Complexed Beads}

Chitosan/surfactant bead stability was less sensitive to $\mathrm{pH}$ than that of alkaline solution-derived and TPP-crosslinked beads (see Figure 2) and, not surprisingly, this stability increased with the surfactant strength (i.e., its tendency to self-associate: $\mathrm{SDS}>\mathrm{NaC}_{12}>\mathrm{NaC}_{10}[45,46]$ ). As the dissolution medium $\mathrm{pH}$, for instance, was lowered from 5.0 to 1.2, the average dissolution times of chitosan $/ \mathrm{NaC}_{10}$ beads only decreased from $\sim 11-12 \mathrm{~h}$ to slightly over $3 \mathrm{~h}$, while the stability of chitosan $/ \mathrm{NaC}_{12}$ and chitosan/SDS beads decreased from roughly 1 day to about $4 \mathrm{~h}$ and from roughly 3.5 to 2 days, respectively. Throughout, the beads formed with stronger surfactants persisted longer, and the 1.8- to 5.9-fold reductions in bead stability as the dissolution medium $\mathrm{pH}$ was decreased from 5.0 to 1.2 were mild compared to the multiple-order-of-magnitude reduction exhibited by the alkaline solution-derived beads and chitosan/TPP beads (Figure 2).

Beads formed from surfactants with longer, dodecyl aliphatic tails (i.e., $\mathrm{NaC}_{12}$ and SDS) formed more stable complexes with chitosan than the shorter-tailed $\mathrm{NaC}_{10}$. This improved stability was qualitatively consistent with previous work on the stability of quaternized chitosan/fatty acid complexes [36], where the increased stability of complexes formed with longer-tailed fatty acids was attributed to the favorable hydrophobic free energy of transfer of aliphatic $\mathrm{CH}_{2}$ groups into the hydrophobic environment of the surfactant/polyelectrolyte complex [36,47]. Since the same hydrophobic effect drives micelle formation, surfactant/polyelectrolyte binding strength tends to scale inversely with the surfactant critical micelle concentration (CMC) $[47,48]$, and thus, surfactant/polyelectrolyte complexes prepared from surfactants with lower CMC values are generally 
more stable to dissolution. Accordingly, the qualitative trend in chitosan/surfactant bead stability shown in Figure 2 is consistent with that of the CMCs, where the CMC of SDS in deionized water (ca. 8 $\mathrm{mM})$ is roughly three times lower than that of $\mathrm{NaC}_{12}(23-24 \mathrm{mM})$, and more than ten times lower than that of $\mathrm{NaC}_{10}(94-96 \mathrm{mM})[45,46]$. Unlike the previous dissolution study (which was conducted in near-neutral phosphate-buffered saline [36]), however, the present study was performed under acidic conditions, where considerable protonation of fatty acid was expected [49]. This protonation likely further weakened fatty acid binding to the chitosan compared to the relatively $\mathrm{pH}$-insensitive SDS.

Interestingly, though surfactant/polyelectrolyte complexation stabilized the chitosan beads under most conditions, beads formed using weakly binding $\mathrm{NaC}_{10}$ and $\mathrm{NaC}_{12}$ dissolved slightly faster at $\mathrm{pH}$ 5.0 than beads prepared in $\mathrm{NaOH}$ solution (see Figure 2). This accelerated dissolution likely stemmed from: (1) a lower initial bead $\mathrm{pH}$ (as the $1 \mathrm{wt} \%$ fatty acid solution was less alkaline than the $0.1 \mathrm{M}$ $\mathrm{NaOH}$ solution); and (2) a higher initial chitosan protonation state caused by the ionic chitosan/fatty acid complexation (which, along with the lower initial $\mathrm{pH}$, reduced the amount of acid diffusion needed to acidify the beads and solubilize the chitosan). These $\mathrm{pH}$ and protonation effects evidently outweighed the added stabilization achieved through the weak chitosan/fatty acid complexation.

Another difference in the dissolution of chitosan/surfactant beads versus the other examined bead types was in the evolution in the bead appearance; specifically, in the outer shells of the surfactant/polyelectrolyte beads frequently delaminating from their internal layers. When chitosan/SDS beads were placed in pH 5.0 dissolution media, for instance, the beads remained relatively unchanged over $20 \mathrm{~h}$ of dissolution, but began to shrink after $40 \mathrm{~h}$ (see Figure 4). After $60 \mathrm{~h}$, the beads shrank even more noticeably, and after $78 \mathrm{~h}$, the outer shells of the beads became transparent and started delaminating (with the bead fully dissolving after 80-90 h). As the dissolution medium $\mathrm{pH}$ was reduced to 4.0, the delamination started to occur earlier, with some deformation occurring after $40 \mathrm{~h}$, pealing of the outer shell noticed after $60 \mathrm{~h}$, and full bead dissolution happening after 3 days (shortly before which the bead became completely transparent; data not shown). The delamination in each case likely reflected the layered structure of the surfactant/polyelectrolyte bead surfaces, which was revealed in earlier studies on their internal morphologies, where similar delamination, buckling, and/or loss of the outer shell during swelling and dissolution also occurred [50,51].

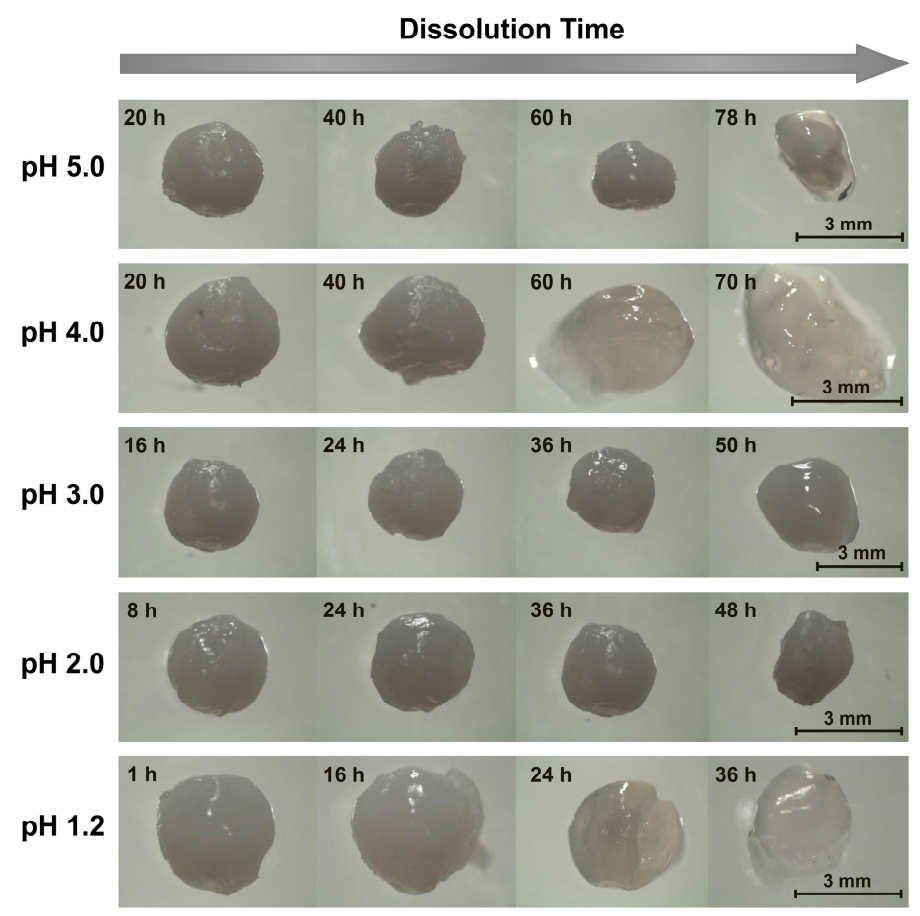

Figure 4. Representative images of chitosan/sodium salts of dodecyl sulfate (SDS) beads dissolving in $\mathrm{pH} 1.2-5.0$ aqueous solutions $([\mathrm{NaCl}]=10 \mathrm{mM})$. 
Interestingly, at lower $\mathrm{pH}$ levels, the outer layer delamination was less evident (Figure 4). Despite remaining virtually unchanged in its first $16 \mathrm{~h}$ at $\mathrm{pH} 3.0$, the beads began deforming after $24 \mathrm{~h}$, and significantly softened after $36 \mathrm{~h}$. This softening was followed by swelling and a further loss in rigidity after $50 \mathrm{~h}$, and then dissolution after $63 \mathrm{~h}$. As the dissolution $\mathrm{pH}$ was lowered further yet (to $\mathrm{pH} 2.0$ ), the beads appeared to maintain their initial properties during the first $8 \mathrm{~h}$, but began to swell after $24 \mathrm{~h}$. After $36 \mathrm{~h}$, they started to shrink (Figure 4), until ultimately dissolving after 50-60 h. Similar (albeit faster) dissolution trends occurred when the SDS was replaced with fatty acids. When $\mathrm{NaC}_{10}$-based beads, for instance, were placed in $\mathrm{pH} 5.0$ media, the beads remained relatively unchanged for the first several hours of dissolution (Figure 5). When the beads were imaged again after $8 \mathrm{~h}$ of dissolution, however, a transparent outer layer formed. After $10 \mathrm{~h}$, though it is not evident in Figure 5, the clear layer started separating from the rest of the bead; and after roughly 11-12 $\mathrm{h}$, the beads completely dissolved. Similarly, at lower $\mathrm{pH}$ levels, this dissociation occurred more rapidly (with complete dissolution happening within just $\sim 3 \mathrm{~h}$ at $\mathrm{pH}$ 1.2). Instead of opacity reduction and delamination initially occurring at the outside of the bead, however, bulk swelling and loss of opacity were more prevalent at lower $\mathrm{pH}$ levels, with surface layer delamination becoming less evident. Fairly similar morphological transitions were also seen for $\mathrm{NaC}_{12}$-based beads (data not shown), whose binding to chitosan was intermediate to that of the strongly binding SDS and weakly binding $\mathrm{NaC}_{10}$.

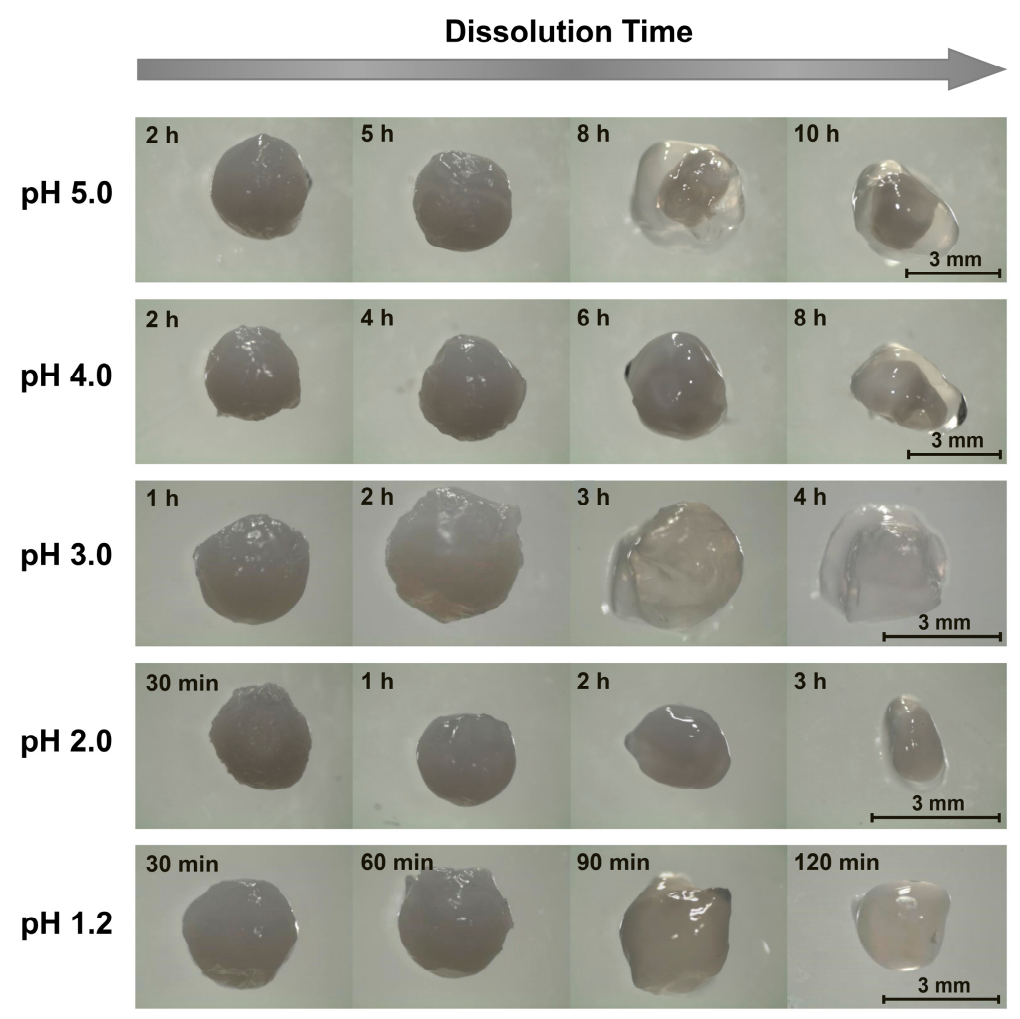

Figure 5. Representative images of chitosan $/ \mathrm{NaC}_{10}$ beads dissolving in $\mathrm{pH} 1.2-5.0$ aqueous solutions $([\mathrm{NaCl}]=10 \mathrm{mM})$.

\subsection{Further Discussion}

Overall, this bead dissolution study demonstrates that: (1) though each of the examined supramolecular chitosan beads ultimately dissolve (or at least shows signs of dissociation) in acidic media, some of these beads are more stable than others; and (2) the order of this stability may depend on whether the media is weakly or strongly acidic. In weakly acidic media (e.g., at pH 5.0, which is not atypical for bioprocesses and food formulations), TPP-crosslinked beads are the most stable, remaining intact (albeit in a slightly more swollen state) for several weeks. In highly acidic environments (such as $\mathrm{pH}$ 1.2, which exists in gastric fluids), however, TPP becomes protonated and, due to its lower anionic 
charge and weaker binding, provides only a minor stabilizing effect under the conditions examined in this work. Further, though earlier publications by Mi et al. reported chitosan/TPP beads prepared using $10 \mathrm{wt} \%$ TPP at a low $\mathrm{pH}$ (which likely resulted in beads with a higher TPP content relative to those prepared in the present study) to remain stable even at $\mathrm{pH} 1.0[26,40]$, these observations were made in experiments where, despite the beads remaining intact, considerable $(>30 \%)$ TPP elution from the beads occurred [26]. These findings suggest that upon eluting this amount of TPP, an equilibrium TPP partitioning between the beads and batch of dissolution media was achieved; and, if a higher media-to-bead ratio was used (or if the dissolution media was regularly replaced as done in our work), further TPP elution and bead dissolution would have eventually occurred. Thus, though the beads prepared via the method of Mi et al. would likely have been more stable than those used here, the magnitude of this stabilization effect remains uncertain.

Unlike the chitosan/TPP gels, beads prepared through chitosan complexation with the strong anionic surfactant SDS are relatively insensitive to $\mathrm{pH}$ and require 2 days to fully dissolve at the gastric $\mathrm{pH}$ of 1.2. Thus, in the limit of low $\mathrm{pH}$, chitosan/SDS beads are the most stable of the beads in our study (though, based on prior work by Mi et al. [31,40] and others [52,53], we expect that similar or greater stability at low $\mathrm{pH}$ might also be achieved using chitosan-based polyelectrolyte complexes, or possibly by increasing the chitosan-bound TPP content within the chitosan/TPP beads [26,40]).

Weak anionic surfactants $\left(\mathrm{NaC}_{10}\right.$ and $\left.\mathrm{NaC}_{12}\right)$ also generate beads whose dissolution stability is less sensitive to $\mathrm{pH}$ than that of beads formed in $\mathrm{NaOH}$ and TPP solutions. Due to their weaker binding to chitosan, however, they do not provide as strong of a stabilizing effect as SDS. Indeed, as discussed in Section 2.3, their use as the gelling agent can reduce bead stability in weakly acidic media (as seen at pH 5.0), and could perhaps be used as a strategy to accelerate (rather than decelerate) bead dissolution under these conditions. Conversely, uncrosslinked chitosan beads (obtained by gelling chitosan in alkaline solution) remain stable for hours in mildly acidic solutions, but dissolve within minutes in highly acidic conditions. Since acid and enzymatically catalyzed hydrolysis of highly deacetylated chitosan (such as used in this work) is expected to be slow [27-29], bead stabilities over timescales ranging from minutes to multiple days (or even weeks/months) can likely be achieved through a judicious selection of supramolecular gelation pathways.

\section{Conclusions}

Stability of chitosan beads formed through alkaline precipitation, ionic crosslinking, and surfactant/polyelectrolyte complexation in acidic dissolution media was compared. The stability of each of these bead types decreased with the increasing acidity of the dissolution media. Under the conditions examined, the uncrosslinked beads remain stable for time periods ranging from minutes to hours, depending on the acid concentration. Chitosan/TPP beads (when prepared using TPP in a modest charge excess at its natural $\mathrm{pH}$ ) are highly sensitive to $\mathrm{pH}$, dissolving within an hour at low $\mathrm{pH}$ levels (e.g., at the gastric fluid $\mathrm{pH}$ of 1.2), but persisting over at least weeks at the mildly acidic $\mathrm{pH}$ of 5.0. Conversely, anionic surfactant-associated chitosan beads are the least sensitive to $\mathrm{pH}$, remain stable in acidic media for up to days at all of the examined $\mathrm{pH}$ levels, and have dissolution properties that can be extensively tuned by varying the surfactant/polyelectrolyte binding strength (by, for instance, changing the anionic surfactant used). Thus, the type of bead that provides the highest stability may depend on whether the dissolution media is weakly acidic (such as may be encountered in food formulations or bioprocessing, where chitosan/TPP beads were the most stable) or strongly acidic (as in the case of gastric fluid where, out of the beads used in this work, chitosan/SDS beads were the most stable). Overall, these findings extend existing guidelines on tuning the stability of supramolecular chitosan gel beads to their diverse technological applications. 


\section{Materials and Methods}

\subsection{Materials}

All experiments were performed using Millipore Direct-Q 3 deionized water (18.2 $\mathrm{M} \Omega \cdot \mathrm{m}$ resistivity). Chitosan $(90 \% \mathrm{DD}$, as determined by $\mathrm{pH}$ titration and viscosity-average molecular weight $=120 \mathrm{kDa}$ [36]), TPP (sodium salt) and $\mathrm{NaC}_{12}$ were purchased from Sigma-Aldrich (St. Louis, MO, USA). SDS was obtained from MP Biomedicals (Solon, OH, USA), HCl was bought from both Sigma-Aldrich (St. Louis, MO, USA) and VWR International, LLC (West Chester, PA, USA), and $\mathrm{NaC}_{10}$ was purchased from Spectrum (New Brunswick, NJ, USA). NaCl and $\mathrm{NaOH}$ were obtained from Fisher Scientific (Fair Lawn, NJ, USA). All materials were used as received.

\subsection{Bead Preparation}

Chitosan solution ( $3 \mathrm{wt} \%$ ) at $\mathrm{pH} 5.0$ was prepared by dissolving chitosan in water, while adding $\mathrm{HCl}$ until the $\mathrm{pH}$ was $5.00 \pm 0.05$. The solution was then equilibrated for $12-16 \mathrm{~h}$ at $30{ }^{\circ} \mathrm{C}$, whereupon the $\mathrm{pH}$ was checked one final time to ensure that it remained stable. The chitosan solution was then loaded into $3 \mathrm{~mL}$ BD Luer-Lok tip syringes, discarding approximately $10 \%$ of the solution at the bottom of the bottle, to avoid loading any undissolved impurities.

To form the beads, the $3 \mathrm{wt} \%$ chitosan solution was added dropwise (at a rate of roughly 30 drops $/ \mathrm{min}$ ) through a 20-gauge syringe needle into gently agitated solutions of either $0.1 \mathrm{M}$ of $\mathrm{NaOH}, 1 \mathrm{wt} \% \mathrm{TPP}, 1 \mathrm{wt} \% \mathrm{NaC}_{10}, 1 \mathrm{wt} \% \mathrm{NaC}_{12}$ or $1 \mathrm{wt} \% \mathrm{SDS}$. All solutions were stored at $30^{\circ} \mathrm{C}$ prior to bead preparation to maintain their temperature above the Krafft point of the least soluble surfactant $\left(\mathrm{NaC}_{12}\right.$ [41]) and ensure that all of the gelling agents remained soluble prior to the chitosan addition. The volume ratio between the receiving ( $\mathrm{NaOH}, \mathrm{TPP}, \mathrm{NaC}_{10}, \mathrm{NaC}_{12}$ or SDS) solutions and the chitosan solution was maintained above 10:1 throughout the dropwise addition process, which in the case of ionically associating TPP, $\mathrm{NaC}_{10}, \mathrm{NaC}_{12}$ and SDS, kept the gelling agent:chitosan charge ratios above 1.7:1, 3.1:1, 2.7:1 and 2.1:1, respectively (i.e., the anionic gelling agent was always in excess). Once the beads were formed, the resulting mixtures were stored in a $30{ }^{\circ} \mathrm{C}$ water bath for at least $24 \mathrm{~h}$ (until the beads were separated from their surrounding solvent for further analysis).

\subsection{Dissolution Experiments}

To test their dissolution stability, chitosan beads (one per each trial) were equilibrated at room temperature in an excess of $10 \mathrm{mM} \mathrm{NaCl}$ solution $\mathrm{pH}$ adjusted to 1.2, 2.0, 3.0, 4.0 or 5.0 using $\mathrm{HCl}$. Dissolution was considered complete when no visible material remained in the dissolution medium. To prepare the beads for dissolution, they were removed from the solutions in which they were formed and rinsed with 5-8 $\mathrm{mL}$ of water before being placed into $1 \mathrm{~L}$ of dissolution medium. Dissolution experiments were then performed by allowing one bead to dissolve in a 1 L Pyrex Vista beaker, agitated with a 5/16" octagonal stir bar at $500 \mathrm{rpm}$. Besides recording the times required for the beads to fully dissolve, evolutions in their size and morphology during dissolution were tracked by periodically imaging them with a Leica EZ4 D (Buffalo Grove, IL, USA) digital stereomicroscope. During each imaging step, the beads were removed from the dissolution medium using a wire mesh, and imaged after removing the surface water with a VWR (West Chester, PA, USA) light duty tissue wiper. The imaged beads were then returned to the dissolution media. For experiments lasting longer than $24 \mathrm{~h}$, the dissolution medium was replaced daily. Each dissolution experiment was reproduced six times.

Author Contributions: Conceptualization, A.J.W. and Y.L.; Experimental work, A.J.W. and K.S.I.; Data analysis, A.J.W., K.S.I. and Y.L.; Paper writing and editing, Y.L. and A.J.W.

Funding: This research received no external funding.

Conflicts of Interest: The authors declare no conflict of interest. 


\section{References}

1. Pillai, C.K.S.; Paul, W.; Sharma, C.P. Chitosan and chitosan polymers: Chemistry, solubility and fiber formation. Prog. Polym. Sci. 2009, 34, 641-678. [CrossRef]

2. Rinaudo, M. Chitin and chitosan: Properties and applications. Prog. Polym. Sci. 2006, 31, 603-632. [CrossRef]

3. Tapola, N.S.; Lyyra, M.L.; Kolehmainen, R.M.; Sarkkinen, E.S.; Schauss, A.G. Safety aspects and cholesterol-lowering efficacy of chitosan tablets. J. Am. Coll. Nutr. 2008, 27, 22-30. [CrossRef] [PubMed]

4. VandeVord, P.J.; Matthew, H.W.; DeSilva, S.P.; Mayton, L.; Wu, B.; Wooley, P.H. Evaluation of the biocompatibility of a chitosan scaffold in mice. J. Biomed. Mater. Res. 2002, 59, 585-590. [CrossRef] [PubMed]

5. Chiappisi, L.; Gradzielski, M. Co-assembly in chitosan-surfactant mixtures: thermodynamics, structures, interfacial properties and applications. Adv. Coll. Int. Sci. 2015, 220, 92-107. [CrossRef] [PubMed]

6. Luo, Y.; Wang, Q. Recent development of chitosan-based polyelectrolyte complexes with natural polysaccharides for drug delivery. Int. J. Biol. Macromol. 2014, 64, 353-367. [CrossRef] [PubMed]

7. Shu, X.; Zhu, K. Controlled drug release properties of ionically cross-linked chitosan beads: The influence of anion structure. Int. J. Pharm. 2002, 233, 217-225. [CrossRef]

8. Garcia-Fuentes, M.; Alonso, M.J. Chitosan-based drug nanocarriers: Where do we stand? J. Controll. Release 2012, 161, 496-504. [CrossRef] [PubMed]

9. Madihally, S.V.; Matthew, H.W.T. Porous chitosan scaffolds for tissue engineering. Biomaterials 1999, 20 , 1133-1142. [CrossRef]

10. Krajewska, B. Application of chitin-and chitosan-based materials for enzyme immobilizations: A review. Enzyme Microb. Technol. 2004, 35, 126-139. [CrossRef]

11. Wahba, M.I. Sodium bicarbonate-gelled chitosan beads as mechanically stable carriers for the covalent immobilization of enzymes. Biotechnol. Prog. 2018, 34, 347-361. [CrossRef] [PubMed]

12. Wang, J.; Chen, C. Chitosan-based biosorbents: Modification and application for biosorption of heavy metals and radionuclides. Bioresour. Technol. 2014, 160, 129-141. [CrossRef] [PubMed]

13. Chatterjee, S.; Lee, D.S.; Lee, M.W.; Woo, S.H. Congo red adsorption from aqueous solutions by using chitosan hydrogel beads impregnated with nonionic or anionic surfactant. Bioresour. Technol. 2009, 100, 3862-3868. [CrossRef] [PubMed]

14. Aider, M. Chitosan application for active bio-based films production and potential in the food industry. LWT-Food Sci. Technol. 2010, 43, 837-842. [CrossRef]

15. Coma, V.; Martial-Gros, A.; Garreau, S.; Copinet, A.; Salin, F.; Deschamps, A. Edible antimicrobial films based on chitosan matrix. J. Food Sci. 2002, 67, 1162-1169. [CrossRef]

16. Sorlier, P.; Denuziere, A.; Viton, C.; Domard, A. Relation between the degree of acetylation and the electrostatic properties of chitin and chitosan. Biomacromolecules 2001, 2, 765-772. [CrossRef] [PubMed]

17. Meng, S.; Liu, Z.; Shen, L.; Guo, Z.; Chou, L.L.; Zhong, W.; Du, Q.; Ge, J. The effect of a layer-by-layer chitosan-heparin coating on the endothelialization and coagulation properties of a coronary stent system. Biomaterials 2009, 30, 2276-2283. [CrossRef] [PubMed]

18. Shu, X.Z.; Zhu, K.J. The influence of multivalent phosphate structure on the properties of ionically cross-linked chitosan films for controlled drug release. Eur. J. Pharm. Biopharm. 2002, 54, 235-243. [CrossRef]

19. Mendes, A.C.; Gorzelanny, C.; Halter, N.; Schneider, S.W.; Chronakis, I.S. Hybrid electrospun chitosan-phospholipids nanofibers for transdermal drug delivery. Int. J. Pharm. 2016, 510, 48-56. [CrossRef] [PubMed]

20. Toivonen, M.S.; Kurki-Suonio, S.; Wagermaier, W.; Hynninen, V.; Hietala, S.; Ikkala, O. Interfacial polyelectrolyte complex spinning of cellulose nanofibrils for advanced bicomponent fibers. Biomacromolecules 2017, 18, 1293-1301. [CrossRef] [PubMed]

21. Calvo, P.; Remunan-Lopez, C.; Vila-Jato, J.L.; Alonso, M.J. Novel hydrophilic chitosan-polyethylene oxide nanoparticles as protein carriers. J. Appl. Polym. Sci. 1997, 63, 125-132. [CrossRef]

22. Saether, H.V.; Holme, H.K.; Maurstald, G.; Smidsrod, O.; Stokke, B.T. Polyelectrolyte complex formation using alginate and chitosan. Carbohydr. Polym. 2008, 74, 813-821.

23. Shchipunov, Y.; Sarin, S.; Kim, I.; Ha, C.-S. Hydrogels formed through regulated self-organization of gradually charging chitosan in solution of xanthan. Green Chem. 2010, 12, 1187-1195. [CrossRef] 
24. Babak, V.G.; Merkovich, E.A.; Desbrieres, J.; Rinaudo, M. Formation of an ordered nanostructure in surfactantpolyelectrolyte complexes formed by interfacial diffusion. Polym. Bull. 2000, 45, 77-81. [CrossRef]

25. Yu, L.; Liu, X.; Yuan, W.; Brown, L.J.; Wang, D. Confined flocculation of ionic pollutants by poly (L-dopa)-based polyelectrolyte complexes in hydrogel beads for three-dimensional, quantitative, efficient water decontamination. Langmuir 2015, 31, 6351-6366. [CrossRef] [PubMed]

26. Mi, F.L.; Shyu, S.S.; Lee, S.T.; Wong, T.B. Kinetic study of chitosan-tripolyphosphate complex reaction and acid-resistive properties of the chitosan-tripolyphosphate gel beads prepared by in-liquid curing method. J. Polym. Sci. B Polym. Phys. 1999, 37, 1551-1564. [CrossRef]

27. Freier, T.; Koh, H.S.; Kazazian, K.; Shoichet, M.S. Controlling cell adhesion and degradation of chitosan films by $\mathrm{N}$-acetylation. Biomaterials 2005, 26, 5872-5878. [CrossRef] [PubMed]

28. Tomihata, K.; Ikada, Y. In vitro and in vivo degradation of films of chitin and its deacetylated derivatives. Biomaterials 1997, 18, 567-575. [CrossRef]

29. Vårum, K.; Ottøy, M.; Smidsrød, O. Acid hydrolysis of chitosans. Carbohydr. Polym. 2001, 46, 89-98. [CrossRef]

30. Huang, Y.; Cai, Y.; Lapitsky, Y. Factors affecting the stability of chitosan/tripolyphosphate micro- and nanogels: Resolving the opposing findings. J. Mater. Chem. B 2015, 3, 5957-5970. [CrossRef]

31. Mi, F.L.; Shyu, S.S.; Kuan, C.Y.; Lee, S.T.; Lu, K.T.; Jang, S.F. Chitosan-polyelectrolyte complexation for the preparation of gel beads and controlled release of anticancer drug. I. Effect of phosphorous polyelectrolyte complex and enzymatic hydrolysis of polymer. J. Appl. Polym. Sci. 1999, 74, 1868-1879. [CrossRef]

32. Remunan-Lopez, C.; Bodmeier, R. Mechanical, water uptake and permeability properties of crosslinked chitosan glutamate and alginate films. J. Controll. Release 1997, 44, 215-225. [CrossRef]

33. Worthen, A.J.; Lapitsky, Y. Stabilization of bioderived surfactant/polyelectrolyte complexes through surfactant conjugation to the biopolymer. Colloid Polym. Sci. 2011, 1589-1596. [CrossRef]

34. Sashiwa, H.; Saimoto, H.; Shigemasa, Y.; Ogawa, R.; Tokura, S. Lysozyme susceptibility of partially deacetylated chitin. Int. J. Biol. Macromol. 1990, 12, 295-296. [CrossRef]

35. Kim, H.; Tator, C.H.; Shoichet, M.S. Chitosan implants in the rat spinal cord: biocompatibility and biodegradation. J. Biomed. Mater. Res. A 2011, 97, 395-404. [CrossRef] [PubMed]

36. Lapitsky, Y.; Zahir, T.; Shoichet, M.S. Modular biodegradable biomaterials from surfactant and polyelectrolyte mixtures. Biomacromolecules 2008, 9, 166-174. [CrossRef] [PubMed]

37. Rusu-Balaita, L.; Desbrieres, J.; Rinaudo, M. Formation of a biocompatible polyelectrolyte complex: Chitosan-hyaluronan complex stability. Polym. Bull. 2003, 50, 91-98. [CrossRef]

38. Jóźwiak, T.; Filipkowska, U.; Szymczyk, P.; Rodziewicz, J.; Mielcarek, A. Effect of ionic and covalent crosslinking agents on properties of chitosan beads and sorption effectiveness of Reactive Black 5 dye. React. Funct. Polym. 2017, 114, 58-74. [CrossRef]

39. Morris, G.A.; Castile, J.; Smith, A.; Adams, G.G.; Harding, S.E. The effect of prolonged storage at different temperatures on the particle size distribution of tripolyphosphate (TPP)—chitosan nanoparticles. Carbohydr. Polym. 2011, 84, 1430-1434. [CrossRef]

40. Mi, F.L.; Shyu, S.S.; Wong, T.B.; Jang, S.F.; Lee, S.T.; Lu, K.T. Chitosan-polyelectrolyte complexation for the preparation of gel beads and controlled release of anticancer drug. II. Effect of pH-dependent ionic crosslinking or interpolymer complex using tripolyphosphate or polyphosphate as reagent. J. Appl. Polym. Sci. 1999, 74, 1093-1107. [CrossRef]

41. McBain, J.; Sierichs, W. The solubility of sodium and potassium soaps and the phase diagrams of aqueous potassium soaps. J. Am. Oil Chem. Soc. 1948, 25, 221-225. [CrossRef]

42. Lipatova, I.; Makarova, L. Effect of hydroacoustic treatment on chitosan dissolution in aqueous acetic acid solutions. Russ. J. Appl. Chem. 2008, 81, 2112-2117. [CrossRef]

43. Wan Ngah, W.; Endud, C.; Mayanar, R. Removal of copper (II) ions from aqueous solution onto chitosan and cross-linked chitosan beads. React. Funct. Polym. 2002, 50, 181-190. [CrossRef]

44. Beukenkamp, J.; Rieman, W.; Lindenbaum, S. Behavior of the condensed phosphates in anion-exchange chromatography. Anal. Chem. 1954, 26, 505-512. [CrossRef]

45. Campbell, A.; Lakshminarayanan, G. Conductances and surface tensions of aqueous solutions of sodium decanoate, sodium laurate, and sodium myristate, at 25 and 35. Can. J. Chem. 1965, 43, 1729-1737. [CrossRef] 
46. Sjostrom, J.; Piculell, L. Interactions between cationically modified hydroxyethyl cellulose and oppositely charged surfactants studied by gel swelling experiments-Effects of surfactant type, hydrophobic modification and added salt. Colloids Surf. A 2001, 183-185, 429. [CrossRef]

47. Goddard, E.D. Polymer surfactant interaction. 2. Polymer and surfactant of opposite charge. Colloids Surf. 1986, 19, 301-329. [CrossRef]

48. Malovikova, A.; Hayakawa, K.; Kwak, J.C.T. Surfactant Polyelectrolyte interactions. 4. Surfactant chain-length dependence on the binding of alkylpyidinium cations to dextran sulfate. J. Phys. Chem. 1984, 88, 1930-1933. [CrossRef]

49. Kanicky, J.R.; Shah, D.O. Effect of premicellar aggregation on the pKa of fatty acid soap solutions. Langmuir 2003, 19, 2034-2038. [CrossRef]

50. Lapitsky, Y.; Eskuchen, W.J.; Kaler, E.W. Surfactant and polyelectrolyte gel particles that swell reversibly. Langmuir 2006, 22, 6375-6379. [CrossRef] [PubMed]

51. Lapitsky, Y.; Kaler, E.W. Formation of surfactant and polyelectrolyte gel particles in aqueous solutions. Colloids Surf. A 2004, 250, 179-187. [CrossRef]

52. Denuziere, A.; Ferrier, D.; Domard, A. Chitosan-chondroitin sulfate and chitosan-hyaluronate polyelectrolyte complexes. Physico-chemical aspects. Carbohydr. Polym. 1996, 29, 317-323. [CrossRef]

53. Fajardo, A.R.; Piai, J.F.; Rubira, A.F.; Muniz, E.C. Time- and pH-dependent self-rearrangement of a swollen polymer network based on polyelectrolytes complexes of chitosan/chondroitin sulfate. Carbohydr. Polym. 2010, 80, 934-943. [CrossRef]

(C) 2019 by the authors. Licensee MDPI, Basel, Switzerland. This article is an open access article distributed under the terms and conditions of the Creative Commons Attribution (CC BY) license (http:// creativecommons.org/licenses/by/4.0/). 